\title{
Prevalence of sexual activity and associated factors in hypertensive males and females in China: A cross-sectional study
}

Xiaojun Chen ${ }^{1 \dagger}$, Qingying Zhang ${ }^{2 \dagger}$ and Xuerui $\operatorname{Tan}^{1 *}$

\begin{abstract}
Background: Hypertension is an important factor contributing to sexual dysfunction. The number of people with hypertension is increasing in China, but research into sexual life, which has implications for quality of life, is limited. We aimed to compare sexual activity and the influence of daily behaviors and sexual domain of hypertensive males and females in south China.

Methods: A cross-sectional study was conducted at the health care center of a university-affiliated hospital from 2007 to 2008. We enrolled 502 subjects with hypertension ( 225 males, $48.79 \pm 7.39$ years old; 277 females, $48.26 \pm 6.93$ years old) and 173 with normotension (82 males, $45.69 \pm 6.58$ years old; 91 females, $46.14 \pm 7.03$ years old), all sexually active. All subjects completed a self-administered questionnaire on sexual activity before a routine physical check-up. Data were collected on sociodemographic and clinical characteristics, use of cigarettes and intake of beverages (including alcohol).

Results: Hypertensive and normotensive subjects differed in frequency of orgasms and of sexual satisfaction, as well as duration of sexual activity. For hypertensive men, low frequency of sexual activity, orgasms and satisfaction were associated with unemployed or retired status than physical labor work (odds ratio [OR] 0.28 [95\% confidence interval (95\% Cl) 0.12-0.69], 0.32 [0.12-0.86], 0.33 [0.19-0.88], respectively; $p<0.05$ ), and long sexual duration was associated with never drinking alcohol than heavy drinking (OR 4.49 [1.28-6.41]). For hypertensive women, low frequency and duration of sexual activity and low satisfaction were associated with never drinking tea than heavy tea drinking (OR 0.42 [0.18-0.96], 0.49 [0.24-0.98], 0.29 [0.14-0.64], respectively; $p<0.05)$. Medication use and electrocardiography results were not associated with sexual activity for hypertensive patients.
\end{abstract}

Conclusions: For hypertensive people in China, lifestyle factors are associated with sexual dysfunction, which differs by the sex of the person. Further research needs to examine serum hormone levels to validate the result.

Keywords: Sexual activity, Hypertensive, Cross-sectional survey, Chinese population

\section{Background}

Sexual problems are a common medical disorder related to illness, psychological status and social lives of the general population [1]. Anxiety and depression are psychological problems implicated in sexual dysfunction (SD), whereas marital status and relationships are socially related factors [2]. Chronic diseases such as diabetes mellitus and hypertension are common risk factors

\footnotetext{
*Correspondence: tanxuerui@vip.sina.com

${ }^{\dagger}$ Equal contributors

'Department of Cardiology, The First Affiliated Hospital of Shantou University Medical College, Shantou, Guangdong 515041, China

Full list of author information is available at the end of the article
}

for SD in men [3-5]. Hypertension may contribute to $\mathrm{SD}$, and many antihypertensive drugs might worsen sexual function because of side effects and decrease patient adherence to anti-hypertensive treatment [6]. Essential hypertension with its chronically evaluated blood pressure is considered a risk factor of cardiovascular disease, which is significantly associated with erectile dysfunction [7]. Erectile dysfunction is more frequent in patients with essential hypertension than normotensive subjects [8-10]. The prevalence of erectile dysfunction ranges from $15 \%$ in Brazil to $54 \%$ in Morocco [11]. The ageadjusted prevalence for Asians is $35 \%$ in Japan, $36.7 \%$ in Hong Kong and $28.3 \%$ in mainland China [12-14].

\section{Ciomed Central}


However, the large variation in prevalence may due to different sample populations, assessment methods and cultures.

Although male sexuality has been studied extensively, female SD in hypertension is less explored, and results vary because of small sample sizes. A study of 216 subjects in Greece found $42.1 \%$ of hypertensive women with $\mathrm{SD}$, and the prevalence decreased with adequate blood pressure control [15]. Another study of 71 women found that most (90\%) with essential hypertensive had SD [16]. In another study, hypertensive women showed lower vaginal lubrication, less frequent orgasms, and more frequent pain than normotensive women [17].

Because sexual activity may vary by culture and by race and ethnicity, the results from other countries may not apply to Chinese populations, whose sexual activity and risk factors are poorly understood. China is facing the critical challenge of the rapidly increasing prevalence of hypertension. The latest survey in a southern China area, Guangdong province, of 85 million residents found a $20.5 \%$ prevalence of hypertension [18]. Research into sexual function in western countries is abundant but limited in China. Thus, we aimed to investigate factors associated with the sexual domain and activity of people with hypertension in southern China.

\section{Methods}

\section{Study design and population}

This study involved a cross-sectional design. Data were collected from 2007 to 2008 in the First Affiliated Hospital of Shantou University Medical College.

The study population was a random cluster sample from company staff or community subjects in the Jinping district of Shantou (Guangdong, China) who were undergoing an annual physical examination in the hospital healthcare center. From 4,020 possible subjects, we recruited 596 with mild to moderate essential hypertension (sitting diastolic blood pressure 90-110 $\mathrm{mmHg}$ and/or sitting systolic blood pressure 140-180 $\mathrm{mmHg}$ from 3 consecutive measurements [19]). Only subjects who had regular sexual intercourse with marital partners were enrolled. People were excluded if they had ischemic heart disease, diabetes, chronic obstructive pulmonary disease, obstructive sleep apnea syndrome, cerebrovascular disease or other diseases that would interfere with sexual function or who used sex-enhancing medication. People using pacemakers and electrocardiography (ECG)-diagnosed atrial fibrillation/flutter were excluded. Finally, 502 subjects with hypertension were enrolled.

Subjects were given a detailed information sheet on the study procedure and were asked to give their signed informed consent to be in the study. The study was approved by the ethics committee of the First Affiliated
Hospital of Shantou University Medical College. Interviews were conducted face to face on an individual basis by a trained researcher who used a structured questionnaire. The collection of all data took approximately $20 \mathrm{~min}$. Patient data were strictly anonymous.

From the same population, we matched subjects with hypertension by age and sex with eligible subjects with normotension as controls and included 173 controls.

\section{Sociodemographics}

The investigator collected data on age, sex, occupational status, education and income for both normotensive and hypertensive subjects. Daily alcohol consumption, cigarette smoking and tea drinking were classified as never, moderate or heavy. We defined moderate smoking as fewer than 5 cigarettes/day and heavy smoking as 20 or more cigarettes/day [20]. Moderate and heavy alcohol consumption were defined as total intake of alcohol, beer or wine $<20 \mathrm{~g} /$ day and $>20 \mathrm{~g} /$ day, respectively [21].

\section{Sexual activity questionnaire}

Subjects completed a self-administered questionnaire about sexual function and activity, as well as satisfaction, that was designed to fit the local culture. It was modified and validated in preliminary tests. It consisted of 9 items: "How frequently do you usually have sexual activity with your partner in a month?", "How frequently do you experience orgasm in a month?" "How many times do you consider your sexual activity satisfactory?" "How long is your usual sexual encounter in minutes?" "Which is the usual coital position adopted: man on top, woman on top or other?", "How do you feel during the sexual activity: comfortable, having chest pain, headache, discomfort?" Male subjects were additionally asked "How long can your erection be maintained in minutes?"

\section{Physical checkup}

Height and weight were measured and the body mass index (BMI) was calculated as weight $/$ height $^{2}\left(\mathrm{~kg} / \mathrm{m}^{2}\right)$. Blood pressure was measured with the patient in a seated position after a 5 -min rest on 3 separate visits. Patients underwent standard 12-lead ECG with use of a Nihon Kohden ECG-9130P-type electrocardiograph.

\section{Statistical analysis}

Chi-square test was used to compare differences in categorical variables. Odds ratios and 95\% confidence intervals $(95 \% \mathrm{CI})$ were calculated to assess the likelihood of characteristics of sexual activity and life factors for hypertensive men and women. Stepwise multinomial logistic regression analyses used to evaluate potential risk factors of sexual domains. The independent variables included in the multivariate regression models were sociodemographic data and 
daily life habits. A $p<0.05$ was considered statistically significant. The power of tests of sexual frequency between each subgroup was $>99 \%$ by NCSS-PASS (2005 version). Statistical analyses involved use of SPSS 15.0 (SPSS Inc., Chicago, IL).

\section{Results}

Demographic characters and prevalence of sexual activity Data were available for 675 subjects who reported having regular sexuality, including 502 with hypertension (225 males, mean age $48.79 \pm 7.39$ years [range 31-65 years]; 277 females, mean age $48.26 \pm 6.93$ years [range 31-63 years]) and 173 with normotension (82 males, mean age $45.69 \pm 6.58$ years; 91 females, mean age $46.14 \pm 7.03$ years (range 32-62 years) (Table 1). All women were less educated than men and were more frequently retired or unemployed than men. The sexes differed in cigarette smoking and alcohol use. Nearly half the enrolled subjects were heavy tea drinkers. Even though the blood pressure of patients with hypertension was mild to moderate, more than half did not use antihypertensive medicine.

Hypertensive and normotensive subjects differed in frequency of orgasm and sexual activity, as well as

Table 1 Demographic and clinical characteristics of enrolled subjects

\begin{tabular}{|c|c|c|c|c|}
\hline \multirow[b]{2}{*}{ Demographic characteristics } & \multicolumn{2}{|c|}{ Hypertensive group } & \multicolumn{2}{|c|}{ Normotensive group } \\
\hline & Men $(n=225)$ & Women $(n=277)$ & Men $(n=82)$ & Women $(n=91)$ \\
\hline Age, mean $\pm S D$ & $48.79 \pm 7.39$ & $48.26 \pm 6.93$ & $45.69 \pm 6.58$ & $46.49 \pm 7.26$ \\
\hline Blood pressure, mean \pm SD & $\begin{array}{l}\text { SBP:149.80 } \pm 11.13 \\
\text { DBP:97.74 } \pm 8.43\end{array}$ & $\begin{array}{l}151.87 \pm 11.13 \\
95.76 \pm 8.04\end{array}$ & $\begin{array}{l}\text { SBP:121.15 } \pm 9.70 \\
\text { DBP:78.90 } \pm 8.67\end{array}$ & $\begin{array}{l}117.10 \pm 11.96 \\
73.85 \pm 9.89\end{array}$ \\
\hline \multicolumn{5}{|l|}{ Educational level } \\
\hline Primary school & $34(15.1)$ & $139(50.2)$ & $7(8.5)$ & $8(8.8)$ \\
\hline High school & $149(66.2)$ & $123(44.4)$ & $29(35.3)$ & $53(58.2)$ \\
\hline University & $42(18.7)$ & $15(5.4)$ & $46(56.2)$ & $30(33.0)$ \\
\hline \multicolumn{5}{|l|}{ Occupational status } \\
\hline Retired or unemployed & $42(18.7)$ & $184(66.4)$ & $36(43.9)$ & $34(37.4)$ \\
\hline Professional & $147(65.3)$ & $59(21.3)$ & $27(32.9)$ & $40(43.9)$ \\
\hline Physical labor & $36(16.0)$ & $34(12.3)$ & $19(23.2)$ & $17(18.7)$ \\
\hline \multicolumn{5}{|l|}{ Income (RMB) } \\
\hline$\leq 1000$ & $37(16.4)$ & $194(70.0)$ & $8(9.7)$ & $47(51.6)$ \\
\hline $1001 \sim 3000$ & $129(57.3)$ & $74(26.7)$ & $62(75.6)$ & $38(41.8)$ \\
\hline$\geq 3000$ & $59(26.2)$ & $9(3.2)$ & $12(14.6)$ & $6(6.6)$ \\
\hline \multicolumn{5}{|l|}{ Cigarette smoking } \\
\hline Never & $85(37.8)$ & $271(97.8)$ & $34(41.5)$ & $86(94.5)$ \\
\hline Moderate & $28(12.4)$ & $6(2.2)$ & $21(25.6)$ & $3(3.2)$ \\
\hline Heavy & $112(49.8)$ & 0 & $27(32.9)$ & $2(2.3)$ \\
\hline \multicolumn{5}{|l|}{ Alcohol consumption } \\
\hline Never & $106(47.1)$ & $262(94.6)$ & $31(37.8)$ & $54(59.3)$ \\
\hline Moderate & 80 (35.6) & $14(5.1)$ & $29(35.4)$ & $25(27.5)$ \\
\hline Heavy & $39(17.3)$ & $1(0.4)$ & $22(26.8)$ & $12(13.2)$ \\
\hline \multicolumn{5}{|l|}{ Tea drinking } \\
\hline Never & $16(7.1)$ & $48(17.3)$ & $16(19.5)$ & $16(17.6)$ \\
\hline Moderate & $53(23.6)$ & $95(34.3)$ & $24(29.3)$ & $34(37.4)$ \\
\hline Heavy & $156(69.3)$ & $134(48.4)$ & $42(51.2)$ & $41(45.0)$ \\
\hline \multicolumn{5}{|l|}{ Medication use } \\
\hline ACEI/ARB & $32(14.2)$ & $23(8.3)$ & - & - \\
\hline$\beta$ blockers & $8(3.6)$ & $9(3.2)$ & - & - \\
\hline $\mathrm{CCB}$ & $28(12.4)$ & $37(13.4)$ & - & - \\
\hline Diuretics or others & $14(6.2)$ & $17(6.1)$ & - & - \\
\hline No medication & $143(63.6)$ & $191(69)$ & - & - \\
\hline
\end{tabular}

Data are number (\%) unless indicated.

SBP, systolic blood pressure; DBP, diastolic blood pressure; ACE1/ARB, angiotensin-converting enzym 1/angiotensin receptor blocker; CCB, calcium channel blocker. 
duration of sexual activity ( $p<0.01$; Table 2$)$. Of the 225 males with hypertension, 57 (25.3\%) reported sexual intercourse less than once per month (low frequency), 77 (34.2\%) more than once per week (high frequency), with the remaining reporting intermediate activity (medium frequency). Of women with hypertension, 102 (36.8\%) reported low-frequency sexual activity and 52 (20.6\%) high-frequency sexual activity. Only 15 men (6.7\%) experienced no orgasm during sexual activity, which coincided with the $6.7 \%$ who reported no sexual satisfaction. However, 172 women (62.1\%) reported no orgasms, but only 80 (28.9\%) considered their sexual life unsatisfactory. About half of the subjects, whether with hypertension or normotension, reported sexual intercourse lasting 6 to $20 \mathrm{~min}$ each time, and 7.5\% with hypertension and $30.1 \%$ with normotension reported the intercourse lasting $<5 \mathrm{~min}$. Man on top appeared to be the favored coital position, with more than $75.5 \%$ reporting this position. In total 422 subjects with hypertension (84.1\%) and 165 with normotension (95.4\%) reported no discomfort during the intercourse.

\section{Factors associated with sexual activity in hypertensive subjects}

For males with hypertension, low frequency of sexual activity and orgasms and sexual satisfaction were associated with unemployed or retired employment status than physical labor (OR 0.28 [95\% CI 0.12-0.69], 0.32 [0.12-0.86], 0.33 [0.19-0.88], respectively; $p<0.05)$. As well, longer duration of sexual activity was associated with never consuming alcohol than heavy drinking (4.49 [1.28-6.41]) (Table 3). For women with hypertension, low frequency and duration of sexual activity and sexual satisfaction were associated with never drinking tea than heavy tea drinking $(0.42$ [0.18-0.96], 0.49 [0.24-0.98], 0.29 [0.14-0.64], respectively; $p<0.05)$. Medication use and ECG results were not associated with sexual activity for hypertensive subjects.

\section{Discussion}

Hypertension is an important factor contributing to SD. Although the number of people with hypertension is increasing in China, research into sexual life, with

Table 2 Sexual activity for subjects with hypertension and normotension and men and women with hypertension

\begin{tabular}{|c|c|c|c|c|c|c|}
\hline & $\begin{array}{l}\text { Hypertension } \\
(n=502)\end{array}$ & $\begin{array}{l}\text { Normotension } \\
(n=173)\end{array}$ & $x^{2}$ & $\begin{array}{l}\text { Men with hypertension } \\
(n=225)\end{array}$ & $\begin{array}{l}\text { Women with hypertension } \\
(n=277)\end{array}$ & $x^{2}$ \\
\hline $\begin{array}{l}\text { Frequency of sexual activity } \\
\text { (times/month) }\end{array}$ & & & 4.22 & & & $13.97^{* *}$ \\
\hline $\operatorname{Low}(\leq 1)$ & 159 (31.7) & $46(26.6)$ & & $57(25.3)$ & $102(36.8)$ & \\
\hline Medium (2-3) & $209(41.6)$ & $67(38.7)$ & & $91(40.4)$ & $118(42.6)$ & \\
\hline High ( $\geq 4)$ & $134(26.7)$ & $60(34.7)$ & & 77 (34.3) & $57(20.6)$ & \\
\hline $\begin{array}{l}\text { Frequency of orgasm } \\
\text { (times/month) }\end{array}$ & & & $10.69^{* *}$ & & & $179.27^{* *}$ \\
\hline $\operatorname{Low}(\leq 1)$ & $187(37.3)$ & $81(46.8)$ & & $15(6.70)$ & $172(62.1)$ & \\
\hline Medium (2-3) & $225(44.8)$ & $53(30.6)$ & & $134(59.6)$ & $91(32.9)$ & \\
\hline High $(\geq 4)$ & 90 (17.9) & $39(22.5)$ & & 76 (33.7) & $14(5.0)$ & \\
\hline $\begin{array}{l}\text { Frequency of sexual satisfaction } \\
\text { (times/month) }\end{array}$ & & & $31.67^{* *}$ & & & $54.91^{* * *}$ \\
\hline $\operatorname{Low}(\leq 1)$ & 95 (18.9) & $67(38.7)$ & & $15(6.70)$ & $80(28.9)$ & \\
\hline Medium (2-3) & $297(59.2)$ & 66 (38.2) & & $136(60.4)$ & $161(58.1)$ & \\
\hline High ( $\geq 4)$ & $110(21.9)$ & $40(23.1)$ & & 74 (32.9) & $36(13.0)$ & \\
\hline $\begin{array}{l}\text { Duration of sexual activity } \\
\text { (min/time) }\end{array}$ & & & $56.35^{* *}$ & & & $25.17^{* *}$ \\
\hline$\leq 5$ & $164(32.7)$ & $35(20.2)$ & & $55(24.4)$ & 109 (39.6) & \\
\hline $6-20$ & $299(59.6)$ & $86(49.7)$ & & $140(62.2)$ & $159(57.4)$ & \\
\hline$\geq 20$ & $39(7.8)$ & $52(30.1)$ & & $30(13.4)$ & $9(3.0)$ & \\
\hline Coital position & & & 1.11 & & & $15.64^{* *}$ \\
\hline Man on top & $379(75.5)$ & $132(76.3)$ & & $151(67.1)$ & $228(82.3)$ & \\
\hline Women on top & $83(16.5)$ & $24(13.8)$ & & $49(21.8)$ & $34(12.3)$ & \\
\hline Other position & $40(8.0)$ & $17(9.9)$ & & $25(11.1)$ & $15(5.4)$ & \\
\hline Sexual feeling & & & & & & 3.39 \\
\hline Comfortable & $422(84.1)$ & $165(95.4)$ & 14.21 & $197(87.6)$ & $198(71.5)$ & \\
\hline Uncomfortable & 79 (15.9) & $8(4.6)$ & & $28(12.4)$ & $79(28.5)$ & \\
\hline
\end{tabular}

Data are number (\%); ${ }^{* *} P<0.01$. 
Table 3 Estimated odds ratios (OR) and $95 \%$ confidence intervals (Cls) for association of demographic characteristics and sexual activity for subjects with hypertension

\begin{tabular}{|c|c|c|c|c|c|c|c|c|}
\hline & \multicolumn{2}{|c|}{ Frequency } & \multicolumn{2}{|c|}{ Orgasm } & \multicolumn{2}{|c|}{ Satisfaction } & \multicolumn{2}{|c|}{ Duration } \\
\hline & Men & Women & Men & Women & Men & Women & Men & Women \\
\hline \multicolumn{9}{|l|}{ Education } \\
\hline Primary school & $1.15(0.42,3.15)$ & $0.51(0.17,1.52)$ & $1.16(0.38,3.51)$ & $0.36(0.11,1.12)$ & $0.69(0.23,2.12)$ & $0.41(0.13,1.32)$ & $0.14(0.04,0.43)^{*}$ & $0.61(0.17,2.15)$ \\
\hline High school & $0.99(0.51,1.94)$ & $0.86(0.31,2.43)$ & $1.29(0.62,2.68)$ & $0.62(0.21,1.82)$ & $1.07(0.52,2.23)$ & $0.76(0.25,2.3)$ & $0.31(0.14,0.66)^{*}$ & $1.41(0.42,4.74)$ \\
\hline University & 1 & 1 & 1 & 1 & 1 & 1 & 1 & 1 \\
\hline \multicolumn{9}{|l|}{ Income status } \\
\hline$\leq 1000$ & $0.55(0.19,1.56)$ & $1.75(0.39,7.84)$ & $0.49(0.16,1.56)$ & $0.35(0.07,1.68)$ & $0.63(0.20,1.96)$ & $0.65(0.13,3.25)$ & $0.51(0.16,1.59)$ & $1.17(0.21,6.66)$ \\
\hline $1001 \sim 3000$ & $0.76(0.41,1.39)$ & $1.74(0.43,7.09)$ & $0.63(0.33,1.22)$ & $0.79(0.18,3.39)$ & $0.71(0.37,1.37)$ & $0.97(0.22,4.39)$ & $0.87(0.45,1.71)$ & $1.73(0.33,9.03)$ \\
\hline$\geq 3000$ & 1 & 1 & 1 & 1 & 1 & 1 & 1 & 1 \\
\hline \multicolumn{9}{|l|}{ Occupation } \\
\hline Unemployed or Retired & $0.28(0.12,0.69)^{*}$ & $0.29(0.14,0.62)$ & $0.32(0.12,0.86)^{*}$ & $1.06(0.43,2.61)$ & $0.33(0.19,0.88)^{*}$ & $0.33(0.15,0.74)^{*}$ & $1.31(0.51,3.42)$ & $1.74(0.25,1.33)$ \\
\hline Professional & $0.96(0.44,2.14)$ & $0.65(0.24,1.72)$ & $0.88(0.37,2.09)$ & $0.85(0.28,2.57)$ & $0.78(0.33,1.84)$ & $0.39(0.14,1.14)^{*}$ & $1.52(0.64,3.62)$ & $1.15(0.37,3.57)$ \\
\hline Physical labor & 1 & 1 & 1 & 1 & & 1 & 1 & 1 \\
\hline \multicolumn{9}{|l|}{ Cigarette smoking } \\
\hline Never & $0.71(0.39,1.27)$ & $2.06(0.25,4.62)$ & $0.63(0.33,1.19)$ & $6.42(5.10,8.16)$ & $0.64(0.34,1.21)$ & $1.47(0.02,8.91)$ & $1.05(0.55,1.97)$ & $7.61(6.35,9.21)$ \\
\hline Moderate & $0.83(0.37,1.85)$ & $2.45(0.43,5.52)$ & $0.95(0.39,2.24)$ & $5.69(4.22,7.34)$ & $1.19(0.51,2.82)$ & $1.29(0.16,10.5)$ & $0.85(0.36,2.03)$ & $8.41(7.22,10.14)$ \\
\hline Heavy & 1 & 1 & 1 & 1 & 1 & & 1 & 1 \\
\hline \multicolumn{9}{|l|}{ Alcohol consumption } \\
\hline Never & $1.24(0.61,2.58)$ & $0.15(0.14,0.17)$ & $1.49(0.67,3.32)$ & $0.45(0.01,27.8)$ & $1.61(0.72,3.59)$ & $0.15(0.14,0.18)$ & $4.49(1.28,6.41)^{*}$ & $0.53(0.03,83.7)$ \\
\hline Moderate & $1.45(0.68,3.03)$ & $0.17(0.15,0.19)$ & $2.08(0.92,4.71)$ & $1.05(0.01,70.1)$ & $1.89(0.84,4.30)$ & $0.14(0.13,0.17)$ & $2.02(0.89,4.55)$ & $1.02(0.05,68.3)$ \\
\hline Heavy & 1 & 1 & 1 & 1 & 1 & 1 & 1 & 1 \\
\hline \multicolumn{9}{|l|}{ Tea drinking } \\
\hline Never & $1.37(0.51,3.71)$ & $0.62(0.31,1.17)$ & $0.72(0.24,2.14)$ & $0.42(0.18,0.96)^{*}$ & $1.08(0.37,3.14)$ & $0.49(0.24,0.98)^{*}$ & $0.93(0.31,2.73)$ & $0.29(0.14,0.64)^{*}$ \\
\hline Moderate & $1.13(0.61,2.09)$ & $0.77(0.46,1.68)$ & $0.95(0.49,1.85)$ & $0.67(0.38,1.19)$ & $0.81(0.41,1.59)$ & $0.76(0.44,1.32)$ & $0.87(0.44,1.71)$ & $0.73(0.41,1.29)$ \\
\hline Heavy & 1 & & 1 & 1 & 1 & 1 & 1 & 1 \\
\hline \multicolumn{9}{|l|}{ Medication } \\
\hline Yes & $1.13(0.66,1.93)$ & $0.84(0.51,1.38)$ & $0.79(0.45,1.43)$ & $0.91(0.53,1.58)$ & $1.07(0.59,1.92)$ & $0.84(0.49,1.41)$ & $1.18(0.65,2.12)$ & $0.72(0.41,1.26)$ \\
\hline No & 1 & & 1 & 1 & 1 & 1 & 1 & 1 \\
\hline \multicolumn{9}{|l|}{ ECG result } \\
\hline Normal & $1.61(0.94,2.76)$ & $0.96(0.59,1.56)$ & $1.63(0.91,2.94)$ & $0.69(0.41,1.19)$ & $1.50(0.83,2.71)$ & $0.91(0.56,1.52)$ & $1.58(0.87,2.86)$ & $0.64(0.37,0.91)$ \\
\hline Abnormal & 1 & 1 & 1 & 1 & 1 & 1 & 1 & 1 \\
\hline
\end{tabular}


implications for quality of life, is limited. We compared sexual activity and the influence of daily behaviors and sexual factors of hypertensive and normotensive males and females in south China and found that lifestyle factors dictated SD in this area. Hypertensive and normotensive subjects differed in frequency of orgasms and sexual satisfaction, as well as duration of sexual activity. For hypertensive men, low frequency of sexual activity and orgasms and sexual satisfaction were associated with unemployed or retired status than physical labor work, and long sexual duration was associated with never drinking alcohol than heavy drinking. For hypertensive women, low frequency and duration of sexual activity and low satisfaction were associated with never drinking tea than heavy tea drinking.

Hypertension, especially mild to moderate, is usually considered an asymptomatic condition [22]. Reports of quality of life with hypertension by the Medical Outcomes Survey SF-36 are abundant in western countries. In China, quality of life was greater for people with normotension than hypertension and greater for patients receiving treatment and with controlled hypertension than for those with poorly controlled hypertension [23]. However, these studies did not focus on sexual activity.

Our results were similar to those of the Caerphilly study of frequency of sexual intercourse for 914 males in the United Kingdom [24]: 197 (21.5\%) had sexual intercourse less than once per month, 231 (25.3\%) twice or more per week, and the remaining 486 (53.2\%) reported intermediate frequency. For our males, the frequency of orgasm was comparable to the reported satisfaction, which suggests that the assessment of sexual satisfaction was mainly based on orgasm experience. Almost twothirds of females experienced no orgasm, but only about one-third were unsatisfied with sexual encounters, which is consistent with reports of middle-aged and older women in the United States [25]. Indeed, female satisfaction in sexual intercourse in both western and Asian societies is related more to the emotional than physical experience [26].

The decreased number of orgasms we found for hypertensive females may be associated with most females being in peri-or postmenopause status. As well, the low sexual activity for females might be the result of declining estrogen and testosterone levels affecting sexual desire [25]. In a cohort of older postmenopausal women (mean age 68 years) with osteoporosis, at baseline, only $46 \%$ reported some sexual activity; the mostreported problem was difficulty in achieving orgasm [27]. Sex hormones are essential for sex-specific behaviors [28], and levels of oestrogens and androgens do account for gender differences in sexuality [29].

We found that sexual activity decreased with age. Because most unemployed or retired men were older subjects, their sexual frequency, orgasm and therefore satisfaction were lower than for younger subjects. We found less tea drinking related to low number of orgasms, satisfaction and sexual duration for hypertensive women. Clinical studies of men suggest that tea drinking may inhibit the proliferation of smooth muscle cells and overall improvement in endothelial function, which may play a role in erectile function. An epidemiological survey found that long-term green tea consumption changed androgen levels in women. However, the precise nature of the association of tea drinking and sexuality needs further study.

In an American study [30], women with high levels of education and income reported a high frequency of sexual activity. As well, those with at least monthly sexual frequency were more likely to have never smoked or currently drink alcohol and had better health status. Results from our study may differ from the previous results because Chinese women tend to drink tea rather than alcohol and to not smoke. Alcohol drinking is a risk factor for hypertension. Recent research of Chinese men found that compared with non-alcohol drinkers, alcohol drinkers who consumed 3 or more drinks a week ( 1 drink equals $12 \mathrm{~g}$ of alcohol) were more likely to report erectile dysfunction as defined by having both sexual dissatisfaction and erectile difficulty $(\mathrm{OR}=2.27)$ [31] In our hypertensive subjects, heavy alcohol consumption was associated with short duration of sexual activity.

\section{Conclusions}

The prevalence of sexual activity differs for men and women with hypertension in China. Lifestyle factors, including educational level, income status and tea drinking may be associated with sexual activity for women and occupational status and alcohol consumption for men. However, further studies are needed with larger samples and investigating serum hormone levels to validate these results.

\section{Limitations}

The main limitation of this study was the self-reporting methodology. Self-reported sexual frequency may be higher than reported because patients may give a socially desirable answer about their sexual function. The items in the self-developed questionnaire may not be sufficient, but enrolled subjects might not be cooperative enough to complete a long questionnaire in the hospital. In addition, several other factors not measured, including side effects of anti-hypertensive medication, may influence sexual activity among people with hypertension, although two-thirds of our subjects with hypertension took no medications. Finally, the sample size of the normotensive group was relatively small as compared with the hypertensive group because most people with 
normotension were unwilling to participate in the study. Persuading healthy people to undergo a medical checkup and provide answers to sensitive issues, even with payment is difficult.

\section{Competing interest}

The authors declare no conflict of interest.

\section{Acknowledgements}

This work was supported by the National Natural Science Foundation of China (No.30771836) and the Provincial Project of Science and Technology Plans of Guangdong (No.2007B031509008).

\section{Author details}

'Department of Cardiology, The First Affiliated Hospital of Shantou University Medical College, Shantou, Guangdong 515041, China. ${ }^{2}$ Department of Preventive Medicine, Shantou University Medical College, Shantou, Guangdong 515041, China.

\section{Authors' contributions}

XC performed the survey and drafted the manuscript. QZ supervised data collection and helped draft the manuscript. XT designed the study and helped interpret the results and modify the manuscript. All authors read and approved the final manuscript.

Received: 20 March 2012 Accepted: 18 May 2012

Published: 18 May 2012

\section{References}

1. Lewis RW, Fugl-Meyer KS, Bosch R, Fugl-Meyer AR, Laumann EO, Lizza E, et al: Epidemiology/risk factors of sexual dysfunction. J Sex Med 2004, 1:35-39.

2. Rust J, Golombok S, Collier J: Marital problems and sexual dysfunction: how are they related? Br J Psychiatry 1988, 152:629-631.

3. Quek KF, Sallam AA, Ng CH, Chua CB: Prevalence of sexual problems and its association with social, psychological and physical factors among men in a Malaysian population: a cross-sectional study. J Sex Med 2008, 5:70-76.

4. Ho TM, Fernández M: Patient's sexual health: do we care enough? J Ren Care 2006, 32:183-186.

5. Abdulah Al Turki Y: Should an inquiry about sexual health, as a reflection of vascular health, be part of routine physicals for young men? Results from an outpatient study. Int J Impot Res 2009, 21:362-365.

6. Kloner RA, Reffelmann T: Sexual function in hypertensive patients receiving treatment. Vasc Health Risk Manag 2006, 2:447-455.

7. Kloner RA: Hypertension as a risk for erectile dysfunction: implications for sildenafil use. J Clin Hypertens 2000, 2:33-36.

8. Croog SH, Levine S, Sudilovsky A, Baume RM, Clive J: Sexual symptoms in hypertensive patients. A clinical trial of antihypertensive medications. Arch Intern Me 1988, 148:788-794.

9. Dusing R: Effect of the angiotensin II antagonist valsartan on sexual function in hypertensive men. Blood Press Suppl 2003, 12:29-34.

10. Doumas M, Tsakiris A, Douma S, Grigorakis A, Papadopoulos A, Hounta A, et al: Factors affecting the increased prevalence of erectile dysfunction in Greek hypertensive compared to normotensive individuals. J Androl 2006, 27:469-477.

11. Nicolosi A, Moreira ED, Shirai M, Bin Mohd Tambi Ml, Glasser DB: Epidemiology of erectile dysfunction in four countries: cross-national study of the prevalence and correlates of erectile dysfunction. Urology 2003, 61:201-206.

12. Berrada S, Kadri N, Mechakra-Tahiri S, Nejjari C: Prevalence of erectile dysfunction and its correlates: a population-based study in Morocco. Int $J$ Impot Res 2003, 15(Suppl 1)S3-S7.

13. Ng EM, Cheng JY: Prevalence and biopsychosocial correlates of erectile dysfunction in Hong Kong: a population-based study. Urology 2007, 70:131-136.

14. Bai $\mathrm{Q}, \mathrm{Xu} \mathrm{QQ}$, Jiang $\mathrm{H}$, Zhang WL, Wang XH, Zhu JC: Prevalence and risk factors of erectile dysfunction in three cities of China: a communitybased study. Asian J Andro 2004, 6:343-348.
15. Tsakiris A, Douma S, Chounta A, Papadopoulos A, Kanellakopoulou K, Giamarellou H: Female sexual dysfunction in essential hypertension: a common problem being uncovered. Hypertens 2006, 24:2387-9232.

16. Kütmeç C, Yurtsever S: Effects of sexual function of essential hypertensions in women. Eur J Cardiovasc Nurs 2011, 1:56-63.

17. Duncan LE, Lewis $C$, Jenkins $P$, Pearson TA: Does hypertension and its pharmacotherapy affect the quality of sexual function in women? Am J Hypertens 2000, 13:640-647.

18. Ma WJ, Tang JL, Zhang YH, Xu YJ, Lin JY, Li JS, et al: Hypertension Prevalence, Awareness, Treatment, Control, and Associated Factors in Adults in Southern China. Am J Hypertens 2012, 25:590-596.

19. Whitworth JA, World Health Organization, International Society of Hypertension Writing Group: 2003 World Health Organization (WHO)/ International Society of Hypertension (ISH) statement on management of hypertension. J Hypertens 2003, 21:1983-1992.

20. Hukkinen M, Kaprio J, Broms U, Koskenvuo M, Korhonen T: Characteristics and consistency of light smoking: long-term follow-up among Finnish adults. Nicotine Tob Res 2009, 11:797-805.

21. Streppel MT, Ocké MC, Boshuizen HC, Kok FJ, Kromhout D: Long-term wine consumption is related to cardiovascular mortality and life expectancy independently of moderate alcohol intake: the Zutphen Study. J Epidemiol Community Health 2009, 63:534-540.

22. Bardage C, Isacson DG: Hypertension and health-related quality of life: an epidemiological study in Sweden. J Clin Epidemiol 2001, 54:172-181.

23. Li W, Liu L, Puente JG, Li Y, Jiang X, Jin S: Hypertension and health related quality of life: an epidemiological study in patients attending hospital clinics in China. J Hypertens 2005, 23:1667-1676.

24. Ebrahim S, May M, Shlomo YB, McCarron P, Frankel S, Yarnell J: Sexual intercourse and risk of ischaemic stroke and coronary heart disease: the Caerphilly study. J Epidemiol Community Health 2002, 56:99-102.

25. Addis IB: Sexual Activity and function in middle-aged and older women. Obstet Gynecol 2006, 107:755-764.

26. Michael $Y$, George D, Tamera $Y$, Raffy $L$ : Sexual satisfaction among married women. Am J of Health Studies 2000, 16:12-73.

27. Modugno F, Ness RB, Ewing S, Cauley JA: Effect of raloxifene on sexual function in older postmenopausal women with osteoporosis. Obstet Gynecol 2003, 101:353-361.

28. Wu MV, Manoli DS, Fraser EJ, Coats JK, Tollkuhn J, Honda S: Estrogen masculinizes neural pathways and sex-specific behaviors. Cell 2009, 139:61-72.

29. Svarstad BL, Cleary PD, Mechanic D, Robers PA: Gender differences in the acquisition of prescribed drugs: an epidemiological study. Med Care 1987, 25:1089-1098.

30. Addis IB, Van Den Eeden SK, Wassel-Fyr CL, Vittinghoff E, Brown JS, Reproductive Risk Factors for Incontinence Study at Kaiser Study Group: Sexual activity and function in middle-aged and older women. Obstet Gynecol 2006, 107:755-764.

31. Lee AC, Ho LM, Yip AW, Fan S, Lam TH: The effect of alcohol drinking on erectile dysfunction in Chinese men. Int J Impot Res 2010, 22:272-278.

\section{doi:10.1186/1471-2458-12-364}

Cite this article as: Chen et al:: Prevalence of sexual activity and associated factors in hypertensive males and females in China: A crosssectional study. BMC Public Health 2012 12:364.

\section{Submit your next manuscript to BioMed Central and take full advantage of:}

- Convenient online submission

- Thorough peer review

- No space constraints or color figure charges

- Immediate publication on acceptance

- Inclusion in PubMed, CAS, Scopus and Google Scholar

- Research which is freely available for redistribution 